\title{
ANALYTICAL AND NUMERICAL ANALYSIS OF COMPRESSIVE DEFORMATION BEHAVIOR OF CAST IN-SITU TIAI MATRIX COMPOSITES REINFORCED WITH CARBIDE PARTICLES
}

\author{
Michaela ŠTAMBORSKÁ, Juraj LAPIN, Oto BAJANA \\ Institute of Materials \& Machine Mechanics, Slovak Academy of Sciences, Bratislava, Slovak Republic, EU, \\ michaela.stamborska@savba.sk, juraj.lapin@savba.sk, oto.bajana@savba.sk
}

https://doi.org/10.37904/metal.2019.746

\begin{abstract}
Analytical and numerical analyses of room temperature compressive deformation behavior of cast in-situ composites with the chemical compositions Ti-44.6Al-7.9Nb-3.6C-0.7Mo and Ti-44.9Al-7.5Nb-4.9C-0.6Mo$0.1 \mathrm{~B}($ at $\%)$ were performed. The microstructural evaluation was carried out by scanning electron microscopy (SEM) and SEM in back scattered electron (BSE) mode. The uniaxial room temperature compression tests were carried out at an initial strain rate of $1 \times 10^{-4} \mathrm{~s}^{-1}$ up to a true strain of $15 \%$. The finite element analysis (FEA) of local equivalent strains supported by quantitative microstructural analysis indicates that the mean length of major axis of fragmented primary carbide particles decreases with increasing local equivalent strain in the compression specimens. The observed differences in compressive work hardening behavior are related to the initial non-uniform deformation, cracking of the primary carbide particles, propagation of cracks in the intermetallic matrix and finally to disintegration of the compressive specimens.
\end{abstract}

Keywords: TiAl, composites, mechanical properties, microstructure, numerical analysis

\section{INTRODUCTION}

Cast TiAl-based alloys are attractive for high-temperature structural applications providing a unique set of physical and mechanical properties for stationary gas turbines, automotive and aircraft engines [1-3]. However, low ductility at room temperature and insufficient strength at high temperatures (above $800{ }^{\circ} \mathrm{C}$ ) limit their extensive industrial application [2]. The high-temperature strength of TiAl-based alloys can be improved by the addition of interstitial elements such as carbon. Alloying with carbon exceeding of about 1 at $\%$ leads usually to formation of coarse primary carbide particles. Additional strengthening of such type of in-situ composites is achieved by precipitation of fine secondary needle-like $\mathrm{Ti}_{3} \mathrm{AIC}$ (P-phase) and plate-like $\mathrm{Ti}_{2} \mathrm{AIC}$ (H-phase) particles in intermetallic matrix similarly to that reported for several low carbon TiAl-based alloys [4-9]. In spite of the previous studies, only limited information is available about room temperature compressive deformation of high carbon containing TiAl-based alloys prepared by melting and casting. Several authors [10-14] have reported that an increase of volume fraction of $\mathrm{Ti}_{2} \mathrm{AIC}$ particles increases room temperature compressive strength of the alloys prepared by arc melting or combustion synthesis.

The aim of this article is analytical and numerical analysis of room temperature compressive deformation of Ti-44.6Al-7.9Nb-3.6C-0.7Mo and Ti-44.9Al-7.5Nb-4.9C-0.6Mo-0.1B (at\%) alloys prepared by vacuum induction melting. Experimental measurements and finite element analysis (FEA) are carried out to characterize the compressive behavior of these alloys. Numerically calculated local strains within the specimens after compression tests are related to the size of fragmented carbide particles.

\section{EXPERIMENTAL PROCEDURES}

The studied alloys with the chemical composition of Ti-44.6Al-7.9Nb-3.6C-0.7Mo and Ti-44.9Al-7.5Nb-4.9C$0.6 \mathrm{Mo}-0.1 \mathrm{~B}$ (at\%) were prepared by vacuum induction melting in the graphite crucibles which was followed by a centrifugal casting (CC) into a cold graphite mould. The as-cast conical samples with a diameter ranging from 15 to $17 \mathrm{~mm}$ and length of $150 \mathrm{~mm}$ were subjected to hot isostatic pressing (HIP) at a temperature of 
$1250^{\circ} \mathrm{C}$ and applied pressure of $200 \mathrm{MPa}$ for $4 \mathrm{~h}$ in argon to remove casting porosity. The hot isostatic pressing was followed by annealing at a temperature of $900^{\circ} \mathrm{C}$ for $25 \mathrm{~h}$ in air.

Cylindrical specimens with a diameter of $8 \mathrm{~mm}$ and length of $12 \mathrm{~mm}$ were used for compression tests. The uniaxial room temperature compression tests were carried out at an initial strain rate of $1 \times 10^{-4} \mathrm{~s}^{-1}$ up to a true strain of $15 \%$ using universal testing machine. The compressive deformation was measured by a contactless laser extensometer.

Metallographic preparation of the samples consisted of standard grinding on abrasive papers and polishing on diamond pastes with various grain sizes up to $0.25 \mu \mathrm{m}$. The microstructural evaluation was carried out by scanning electron microscopy (SEM) and SEM in back scattered electron (BSE) mode. The quantitative metallographic analysis was performed on digitalized BSE micrographs using computerized image analyzer. The achieved microstructural data were treated statistically.

Software Ansys Workbench was used for numerical simulation of compressive specimen with geometry built as a 3D cylinder with a diameter of $8 \mathrm{~mm}$ and length of $12 \mathrm{~mm}$. Material model was built up using the achieved experimental data from the compression tests at room temperature and mesh was create by deformable hexahedron elements with a size of $0.6 \mathrm{~mm}$.

\section{RESULTS}

\subsection{Microstructural characterization}

The phase composition of the studied centrifugally cast in-situ composites with the chemical composition Ti44.6Al-7.9Nb-3.6C-0.7Mo and Ti-44.9Al-7.5Nb-4.9C-0.6Mo-0.1B (at\%) has been analyzed recently by Štamborská and Lapin [2]. Figure 1 show the typical microstructures of the compression specimens C3.6 and C4.9 before testing. The microstructure of the specimens consists of intermetallic Y(TiAl)-based matrix and coarse primary $\mathrm{H}-\mathrm{Ti}_{2} \mathrm{AIC}$ particles [2]. The carbide particles, which are formed during solidification in the melt, are relatively homogeneously distributed in the intermetallic matrix, as seen in Figures $\mathbf{1 a}$ and $\mathbf{1 b}$.
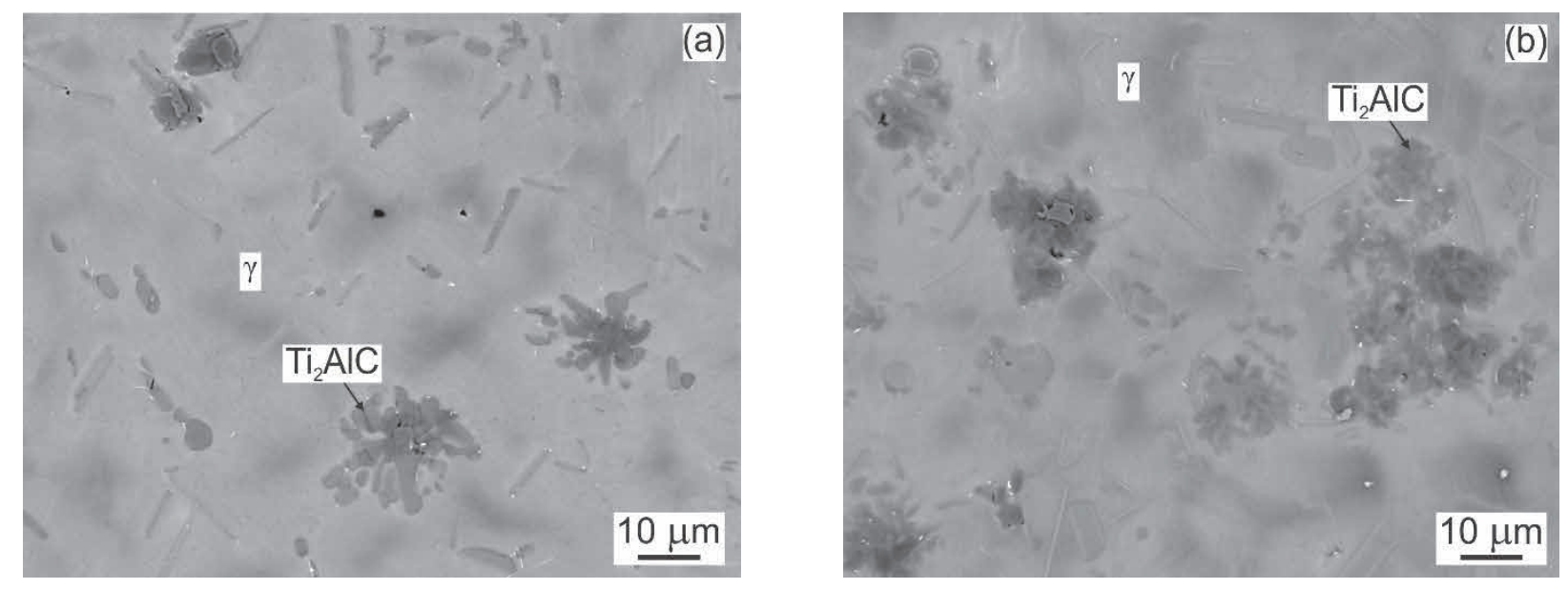

Figure 1 BSE micrographs showing the typical microstructure of the compression specimens before testing:

(a) In-situ composite C3.6; (b) In-situ composite C4.9

Figure 2 shows the typical examples of distribution curves of the measured length of major axis of the primary carbide particles before compression testing (BC). The length of the major axis of both in-situ composites C3.6 (Figure 2a) and C4.9 (Figure 2b) can be fitted by a log-normal distribution function. The increase of the carbon content from 3.6 to 4.9 at\% leads to an increase in volume fraction of the primary carbide particles from 14.9 to $20.1 \mathrm{vol} \%$. 

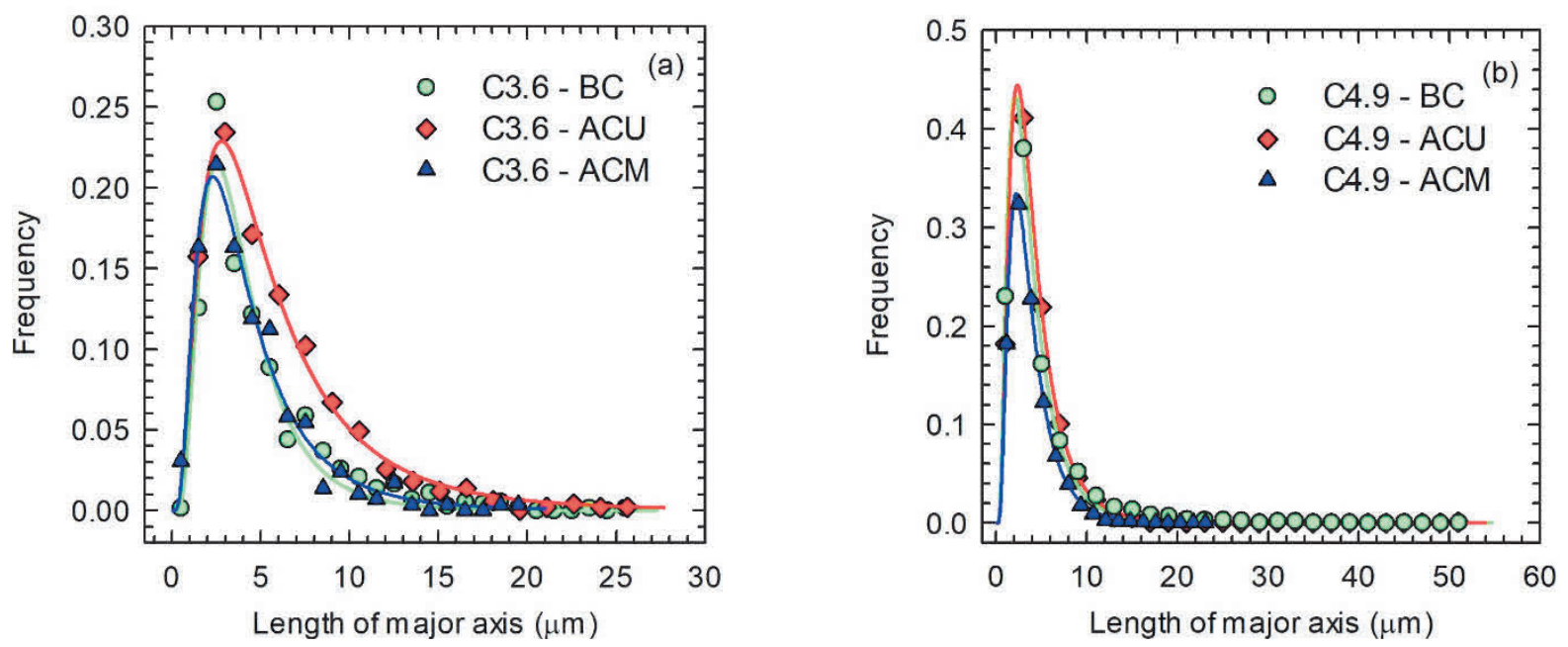

Figure 2 Log-normal distribution curves of length of major axis of primary $\mathrm{Ti}_{2} \mathrm{AlC}$ particles before and after compression testing of in-situ composites: (a) C3.6; (b) C4.9

\subsection{Analytical and numerical analysis of compressive behavior}

The compression true stress-true strain curves were calculated from the measured engineering compression stress-strain data using the procedure described elsewhere [15]. Figure 3 shows the typical true stress-true strain compression curves and results of numerical calculations using FEA software ANSYS. It is clear from this figure that the numerical calculations are in a very good agreement with the experimentally measured true stress-true strain curves.

Figure 4 shows the dependence of the calculated work hardening rate (WHR) on true stress for specimens C3.6 and C4.9. Three different regions for both specimens can be well identified on the WHR curves. The region I is characterized by a fast decrease of the WHR with true stress up to $900 \mathrm{MPa}$ and $1000 \mathrm{MPa}$ for the specimen C4.9 and C3.6, respectively. The region II observed at a true stresses from 900 to $1170 \mathrm{MPa}$ and from 1000 to $1350 \mathrm{MPa}$ for the specimen C4.9 and C3.6, respectively, are characterized by a gradual decrease of the WHR. The fast decrease of the WHR in the region III at a true stress higher than 1170 and $1350 \mathrm{MPa}$ for the specimen C4.9 and C3.6, respectively, indicates an intensive softening connected with microstructure degradation during compression testing.

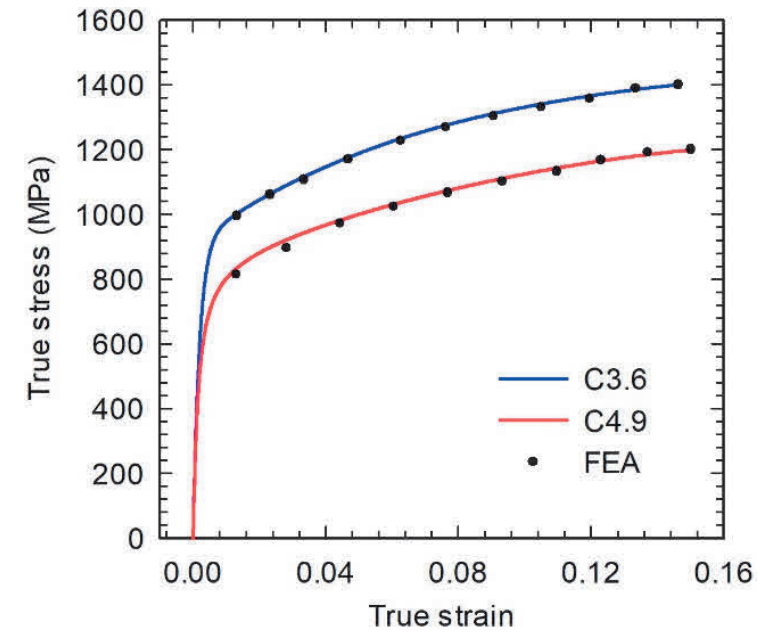

Figure 3 Dependence of compressive true stress on true strain for in-situ composites C3.6 and C4.9

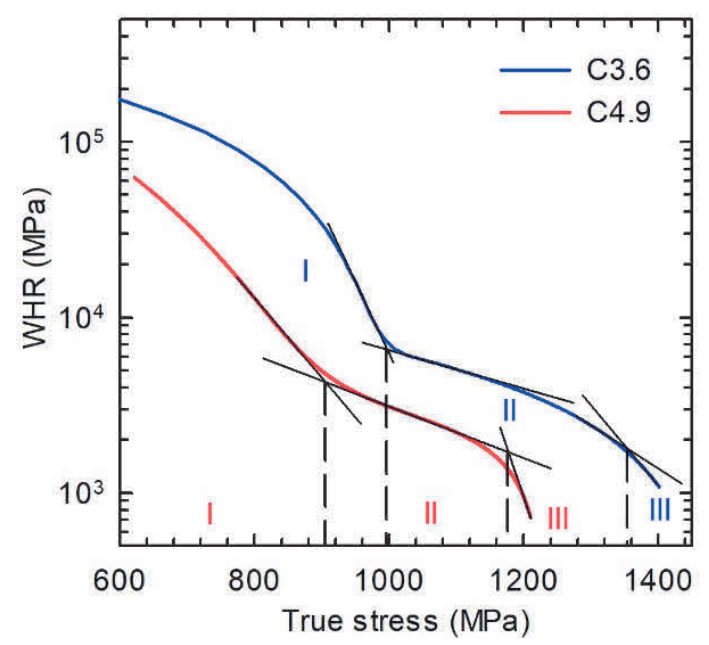

Figure 4 Dependence of work hardening rate on true stress for in-situ composites C3.6 and C4.9 
Figure 5 shows longitudinal section of the compression specimen C4.9 and corresponding 3D numerical calculations of equivalent plastic strains. The slightly barreled shape of the specimen tested to a true strain of $15 \%$ (Figure 5a) corresponds quite well to the calculated one (Figure 5b). The FEA indicates the inhomogeneous distribution of the local calculated strains. The highest equivalent strain of $20 \%$ calculated for the compression specimen $\mathrm{C} 4.9$ is achieved in the middle region marked by the red rectangle (M) in Figure $\mathbf{5 a}$. The lowest equivalent strain of $6 \%$ (Figure $\mathbf{5 b}$ ) is achieved in the vicinity of the contact areas of the specimen with the pressure plates of the testing machine marked by the blue rectangles $(U)$.
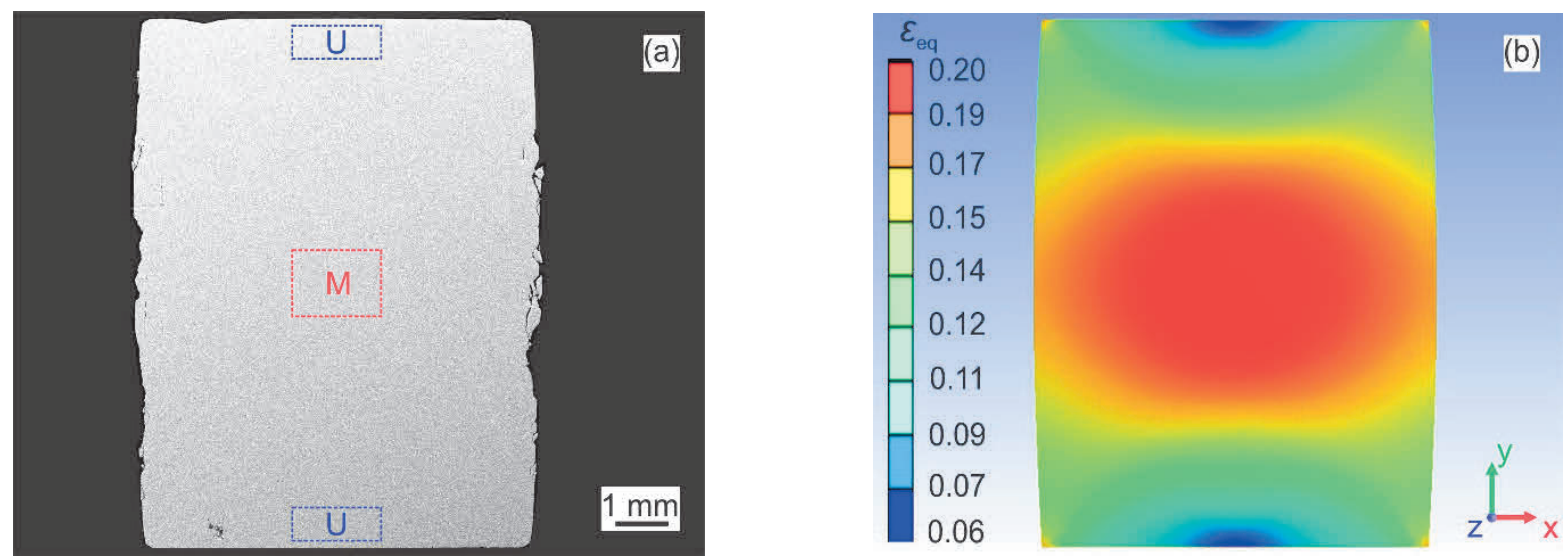

Figure 5 Longitudinal section of the compression specimen C4.9 tested to a true strain of $15 \%$ and corresponding 3D numerical modelling of equivalent plastic strains: (a) SEM macrostructure and (b) FEA

\section{DISCUSSION}

The high WHR measured in the region II (Figure 4) can be attributed to an increase of dislocation density and mechanical twinning in the $y$ matrix $[16,17]$. Benitez et al. [18] have shown that the compressive strength of polycrystalline $\mathrm{Ti}_{2} \mathrm{AIC}$ depends strongly on grain size and increases from about 350 to about $1200 \mathrm{MPa}$ by decreasing grain size from 44 to $4.2 \mu \mathrm{m}$. Taking into account indentation modulus of the matrix of $165 \mathrm{GPa}$, indentation modulus of the carbide particles of $231.1 \mathrm{GPa}$ and strain of $0.4 \%$ corresponding to the offset $0.2 \%$ yield strength of the in-situ composite, one can estimate a stress of about $930 \mathrm{MPa}$ which is carried by the coarse carbide particles [19]. This stress can be sufficiently high to cause plastic deformation of some favorably oriented primary $\mathrm{Ti}_{2} \mathrm{AlC}$ particles with the basal planes oriented at approximately $45^{\circ}$ to load axis (soft orientations) [20]. The particles whose basal planes are parallel to the load axis can deform by kinking in the areas of maximum shear stress. The coarse $\mathrm{Ti}_{2} \mathrm{AIC}$ particles whose basal planes are perpendicular to the load axis undergo only elastic deformation. Figure 6 shows microstructure on longitudinal sections of the compression specimens C3.6 and C4.9 deformed to a true strain of $15 \%$. The local strains up to $21 \%$ in the region $\mathrm{M}$ for the specimen $\mathrm{C} 3.6$ lead to fragmentation of the $\mathrm{Ti}_{2} \mathrm{AIC}$ particles, as seen in Figure $\mathbf{6 a}$. The local strains up to $20 \%$ in the region $M$ for the specimen C4.9 (Figure 6 b) lead to an intensive fragmentation of the $\mathrm{Ti}_{2} \mathrm{AIC}$ particles and crack initiation. Such cracks propagate within the matrix, carbide particles and along the $\mathrm{Y}$ grain boundaries. Figure $\mathbf{5 a}$ indicates that the compressive deformation in the vicinity of the free surface is connected with the initiation and propagation of numerous large cracks which can lead even to the release of some grains from the specimen surface. Figure $\mathbf{6 c}$ and Figure $\mathbf{6 d}$ show crack propagation within the matrix and carbide particles in the vicinity of free surface of the compression specimen C3.6 and C4.9 at local strains of $14 \%$. Besides the fragmentation of the coarse carbide particles and formation of cracks along the particle/matrix interfaces, the softening of the composites is connected with the initiation and propagation of cracks in the vicinity of the specimen free surface. Figure 2 summarizes the results of statistical evaluation of length of major axis of the fragmented carbide particles after the compression in the regions $M(A C M)$ and $U$ (ACU). The fragmentation leads to a significantly smaller mean length of major axis and is more intensive in the region $\mathrm{M}$ compared to that in the regions $U$. 

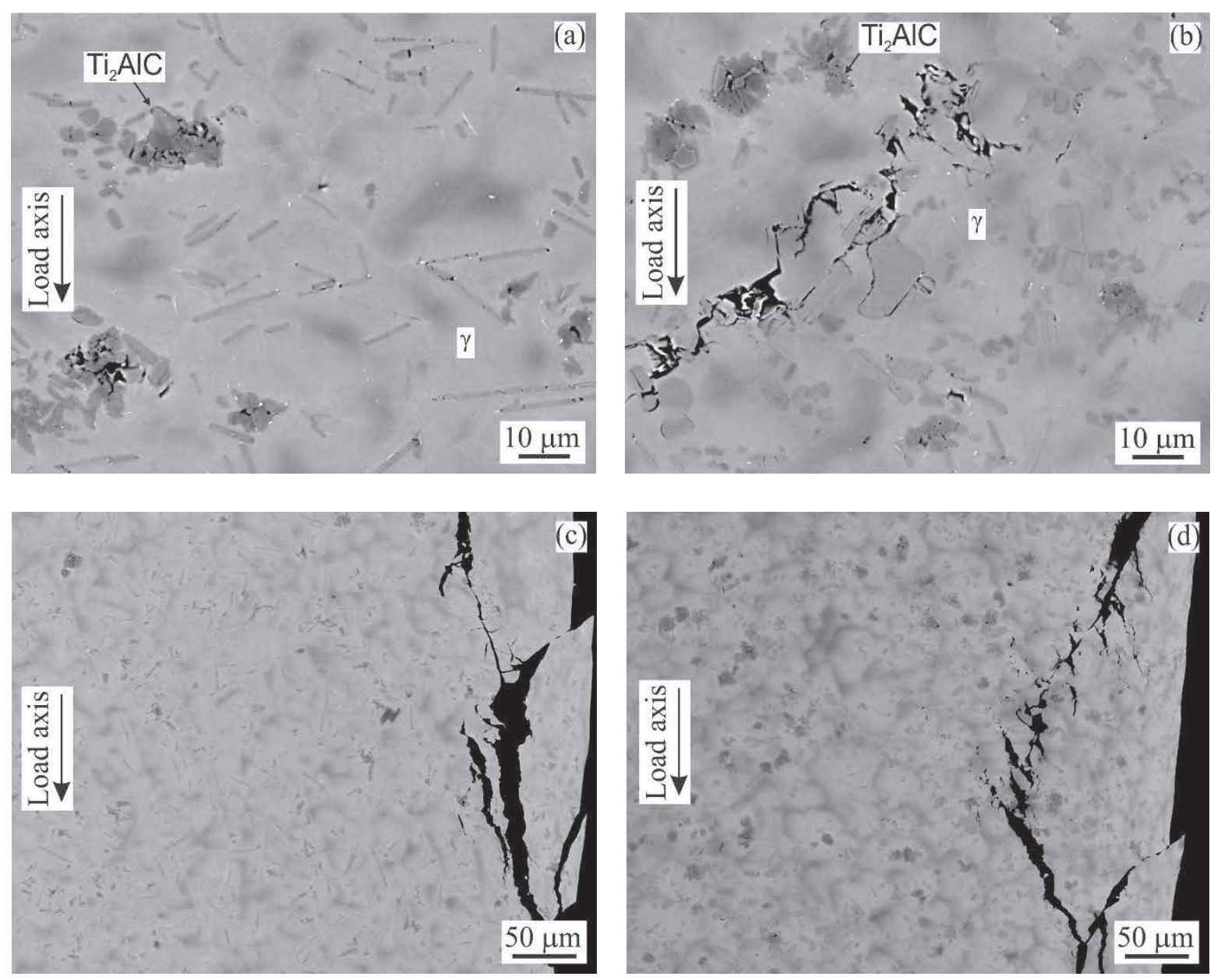

Figure 6 BSE micrographs showing microstructure on longitudinal sections of compression specimens:

(a) Region M of the specimen C3.6; (b) Region M of the specimen C4.9; (c) Vicinity of free surface of the specimen C3.6; (d) Vicinity of free surface of the specimen C4.9

\section{CONCLUSIONS}

The achieved results of analytical and numerical analysis of compressive deformation of Ti-44.6Al-7.9Nb-3.6C0.7Mo and Ti-44.9Al-7.5Nb-4.9C-0.6Mo-0.1B (at\%) in-situ composites can be summarized as follows:

- $\quad$ The local equivalent strains in the compression specimens are numerically calculated using finite element analysis software ANSYS and related to the size of fragmented primary carbide particles. The mean length of major axis of fragmented carbide particles decreases with increasing local equivalent strain in the compression specimens.

- Three regions characterize the evolution of the work hardening rate with the true stress in the studied in-situ composites. The differences in work hardening behavior of the in-situ composite C3.6 and C4.9 can be related to the initial non-uniform deformation, cracking of primary carbide particles, crack propagation and release of some grains from the free surface of the specimens.

\section{ACKNOWLEDGEMENTS}

This work was financially supported by the Slovak Research and Development Agency under the contract APVV-15-0660. 


\section{REFERENCES}

[1] BEWLAY, B. P., NAG, S., SUZUKI, A. and WEIMER, M. J. TiAl alloys in commercial aircraft engines. Mater. High Temp. 2016. vol. 33, pp. 549-559. DOI: 10.1080/09603409.2016.1183068.

[2] ŠTAMBORSKÁ, M., LAPIN, J. and BAJANA, O. Effect of carbon on the room temperature compressive behaviour of Ti-44.5Al-8Nb-0.8Mo-xC alloys prepared by vacuum induction melting. Kovove Mater. 2018. vol. 56, no. 6, pp. 349-356. DOI: 10.4149/km.2018.6.349.

[3] BÜNCK, M., STOYANOV, T., SCHIEVENBUSCH, J., MICHELS, H. and GUßFELD, A. Titanium Aluminide Casting Technology Development. JOM. 2017. vol. 69, pp. 2565. DOI: 10.1007/s11837-017-2534-0

[4] TIAN, W.H. and NEMOTO, M. Effect of carbon addition on the microstructures and mechanical properties of $\mathrm{Y}$ TiAl alloys. Intermetallics. 1997. vol. 5, pp. 237-244. DOI: 10.1016/S0966-9795(96)00086-6.

[5] APPEL, F., OEHRING, M. and WAGNER, R. Novel design concepts for gamma-base titanium aluminide alloys. Intermetallics. 2000. vol. 8, pp. 1283-1312. DOI: 10.1016/S0966-9795(00)00036-4.

[6] WANG, L., OEHRING, M., LORENZ, U., STARK, A. and PYCZAK, F. New insights into perovskite-Ti3AIC precipitate splitting in a Ti-45Al-5Nb-0.75C alloy by transmission electron microscopy. Intermetallics. 2018. vol. 100, pp. 70-76. DOI: 10.1016/j.intermet.2018.06.006.

[7] ČEGAN, T. and SZURMAN, I. Thermal stability and precipitation strengthening of fully lamellar Ti-45Al-5Nb-0.2B0.75C alloy. Kovove Mater. 2017. vol. 55, pp. 421-430. DOI: 10.4149/km_2017_6_421.

[8] KAMYSHNYKOVA, K. and LAPIN, J. Grain refinement of cast peritectic TiAl-based alloy by solid-state phase transformations. Kovove Mater. 2018. vol. 56, no. 5, pp. 277-287. DOI: 10.4149/km_2018_5_277.

[9] AIKIN, R.M. The mechanical properties of in- situ composites. JOM. 1997. vol. 49, pp. 35-39. DOI: $10.1007 / \mathrm{BF} 02914400$.

[10] SHU, S., QIU, F., JIN, S., LU, J. and JIANG, Q. Compression properties and work-hardening behavior of $\mathrm{Ti}_{2} \mathrm{AlC} / \mathrm{TiAl}$ composites fabricated by combustion synthesis and hot press consolidation in the Ti-Al-Nb-C system. Mater. Des. 2011. vol. 32, pp. 5061-5065. DOI: 10.1016/j.matdes.2011.05.041.

[11] FANG, H., CHEN, R., YANG, Y., SU, Y., DING, H., GUO, J. and FU, H. Role of graphite on microstructural evolution and mechanical properties of ternary TiAl alloy prepared by arc melting method. Mater. Des. 2018. vol. 156, pp. 300-310. DOI: 10.1016/j.matdes.2018.06.048.

[12] SONG, X., CUI, H., HAN, Y., HOU, N., WEI, N., DING, L. and SONG, Q. Effect of carbon reactant on microstructures and mechanical properties of TiAl/Ti2AlC composites. Mater. Sci. Eng. A. 2017. vol. 684, pp. 406412. DOI: 10.1016/j.msea.2016.12.069.

[13] TIAN, W.H. and NEMOTO, M. Effect of carbon addition on the microstructures and mechanical properties of $\mathrm{Y}$ TiAl alloys. Intermetallics. 1997. vol. 5, pp. 237-244. DOI: 10.1016/S0966-9795(96)00086-6.

[14] PAUL, J.D.H., APPEL, F. and WAGNER, R. The compression behaviour of niobium alloyed $y$-titanium aluminides. Acta Mater. 1998. vol. 46, pp. 1075-1085. DOI: 10.1016/S1359-6454(97)00332-7.

[15] ŠTAMBORSKÁ, M. and LAPIN, J. Effect of anisotropic microstructure on high-temperature compression deformation of CoCrFeNi based complex concentrated alloy. Kovove Mater. 2017. vol. 55, pp. 369-378. DOI: 10.4149/km_2017_6_369.

[16] VIGUIER, B. Dislocation densities and strain hardening rate in some intermetallic compounds. Mater. Sci. Eng. A. 2003. vol. 349, pp. 132-135. DOI: 10.1016/S0921-5093(02)00785-2.

[17] APPEL, F., SPARKA, U. and WAGNER, R. Work hardening and recovery of gamma base titanium aluminides. Intermetallics. 1999. vol. 7, pp. 325-334. DOI: 10.1016/S0966-9795(98)00109-5.

[18] BENITEZ, R., GAO, H., O'NEAL, M., LOVELACE, P., PROUST, G. and RADOVIC, M. Effects of microstructure on the mechanical properties of $\mathrm{Ti}_{2} \mathrm{AIC}$ in compression. Acta Mater. 2018. vol. 143, pp. 130-140. DOI: 10.1016/j.actamat.2017.10.019.

[19] LAPIN, J., ŠTAMBORSKÁ, M., KAMYSHNYKOVA, K., PELACHOVÁ, T., KLIMOVÁ, A. and BAJANA, O. Room temperature mechanical behaviour of cast in-situ TiAl matrix composite reinforced with carbide particles. Intermetallics. 2019. vol. 105, pp. 113-123. DOI: 10.1016/j.intermet.2018.11.007.

[20] BARSOUM, M.W. and RADOVIC, M. Elastic and mechanical properties of the MAX phases. Annu. Rev. Mater. Res. 2011. vol. 41, pp. 195-227. DOI: 10.1146/annurevmatsci-062910-100448. 